(Forthcoming at Inquiry. Please cite the published version when it is available.)

\title{
Rational Conceptual Conflict and the Implementation Problem
}

\begin{abstract}
Conceptual engineers endeavor to improve our stock of concepts. But their endeavors face serious practical difficulties. One such difficulty - rational conceptual conflict - concerns the degree to which agents are incentivized to impede the efforts of conceptual engineers, especially in many of the contexts within which conceptual engineering is viewed as a worthwhile pursuit. Under such conditions, the already difficult task of conceptual engineering becomes even more difficult. Consequently, if they want to increase their chances of success, conceptual engineers should pay closer attention to - and devise strategies to mitigate - rational conceptual conflict. After outlining the phenomenon at greater length and mapping its connections to other similar practical problems (Section 1), I explore the dynamics of such conflict by way of several detailed case studies (Section 2). In particular, I focus on cases driven by material, social, and moral incentives. I then consider some important methodological implications of rational conceptual conflict (Section 3). Among other things, I argue that conceptual engineers should focus more heavily on cultivating settings that modify the payoffs and penalties associated with conceptual conflict. By such indirect means, they can incentivize conceptual cooperation rather than conflict, thus making it easier to achieve success in conceptual engineering. Section 4 concludes.
\end{abstract}

Keywords: conceptual engineering; conceptual conflict; ameliorative projects; the Implementation Problem 


\section{Introduction}

Conceptual engineers are in the business of assessing and evaluating concepts. If necessary, they attempt to repair, replace, or even abandon them. Naturally, such attempts raise important practical difficulties. One understudied and underappreciated practical problem facing conceptual engineers is the degree to which conceptual conflict can be rational. Conceptual conflict occurs when an agent (or group of agents) deliberately attempts to block or otherwise impede the conceptual engineering efforts of others. Importantly, we'll see that our lives are often structured such that the initiation or continuation of conceptual conflict become appropriate means to our chosen ends. Under conditions where conceptual conflict is incentivized, the already difficult task of engineering concepts becomes considerably more difficult. Accordingly, to increase the chances that their projects succeed, conceptual engineers ought to pay closer attention to - and, if possible, devise strategies to mitigate - problems created by rational conceptual conflict.

In Section 1 I outline the problem posed by rational conceptual conflict at greater length, as well as discussing its relationship to other already recognized practical impediments to successful conceptual engineering. I argue both that the sort of incentives which drive conceptual conflict are quite common and that even forms of conceptual engineering where success is seemingly easiest to achieve will often face difficulties which we should not underestimate.

In Section 2 I explore the dynamics of rational conceptual conflict. While idealized descriptions of conceptual engineering tend to focus on the degree to which it is driven by paradigmatically philosophical considerations (such as whether a concept satisfies certain theoretical desiderata), much ordinary conceptual conflict is driven by the pursuit of things like wealth, power, and social status, desire for which can often override more distinctively philosophical aims. Accordingly, I discuss several examples of rational conceptual conflict driven 
by the pursuit of material benefits, social benefits, and by underlying moral commitments. Though the details differ from case to case, each involves agents attempting to secure benefits and avoid costs by instigating conceptual conflict.

In Section 3 I discuss some important methodological implications of rational conceptual conflict. Negatively, the possibility of such conflict sometimes militates entirely against attempting to engineer a concept. Sometimes conceptual conflict simply makes it impossible for us to successfully engineer concepts. Other times, while not rendering success impossible, conflict brings expected costs which outweigh the expected benefits of success in conceptual engineering. Positively, the recognition that conceptual conflict is often driven by incentives allows conceptual engineers to more readily develop effective strategies to mitigate it. Rather than focusing on potentially fruitless strategies that ignore the underlying incentives, I suggest that conceptual engineers should focus more heavily on cultivating settings that modify the payoffs and penalties associated with conceptual conflict. By such indirect means we can disincentivize conceptual conflict while at the same time incentivizing greater levels of conceptual cooperation. Section 4 concludes.

\section{The Problem of Rational Conceptual Conflict}

At its most general, conceptual engineering is the "critical/constructive enterprise of assessing and improving our representational devices" (Cappelen, 2018: 3). Our representational devices henceforth concepts - can be defective, and so we should try to repair them whenever possible. ${ }^{1}$

\footnotetext{
${ }^{1}$ There are several competing theories regarding the nature of concepts and what it is to engineer them. Indeed, on some accounts it is a misnomer to say it is concepts we engineer and not, say, word-meanings. Setting such disputes aside in this paper, I assume that my claims regarding rational conceptual conflict apply to all extant theories of conceptual engineering, writing of concepts only for convenience. For more on competing theories of conceptual engineering, see Cappelen (2018: 163-99).
} 
When we endorse some strategy about how best (or whether) to repair a defective concept, let's say that we endorse an ameliorative proposal (Haslanger, 2012). In the same vein, let's call

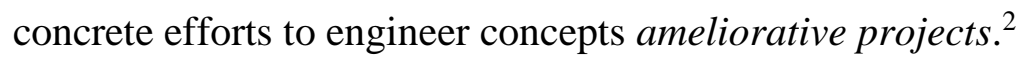

The details of any given ameliorative project will vary from case to case, with some calling for 'mere' conceptual revision, others requiring complete conceptual abandonment, and so on. Similarly, ameliorative projects vary in scale. In some cases, conceptual engineers will be satisfied once a relatively small community of concept-users adopts the ameliorative proposal, while in others much larger numbers will be involved. Crucially, though, it is important to recognize that advancing an ameliorative proposal, no matter its motivation or intended scope, is just the first step towards engineering some concept. Conceptual engineers also need to be able to implement their preferred proposals - that is, they need to develop feasible ameliorative projects whereby their ameliorative ambitions are achieved. This immediately raises pressing practical problems for conceptual engineers. In addition to the identification and categorization of defective concepts, they need to develop ways to successfully carry out their projects; and to best carry out their projects, they must understand the sorts of practical problems they're likely to encounter. Call this the Implementation Problem (Cappelen, 2020; Jorem, forthcoming).

Some barriers to successful implementation have already been recognized in the literature on conceptual engineering. For instance, the success of certain ameliorative projects crucially depends upon the ability of people to reason competently with newly engineered concepts. However, people will vary in their ability to understand and use new concepts (Fischer, 2020). When too many people are unable to understand the relevant proposals, ameliorative projects

\footnotetext{
2 'Ameliorative' here should be read as elliptically referring to the values and goals of the agent endorsing the ameliorative proposal and project. People will naturally disagree over whether any given proposal is one that will improve the concept in question. In other words, they will often disagree about which proposals are truly ameliorative.
} 
might fail. For another, if metasemantic externalism is true, then facts about the history of a concept, facts about how a concept is currently used, facts about how experts use a concept, and facts about the environment are all relevant to determining the meaning of a concept. Since we lack control over such facts, conceptual engineering will be extremely difficult (Cappelen, 2018: 72-4).

The practical problem outlined in this paper - rational conceptual conflict - shares more in common with the latter than the former. Broadly speaking, conceptual conflict occurs when an agent (or group of agents) deliberately attempts to impede the ameliorative projects of another agent (or group of agents). Importantly, these attempts are often instrumentally rational. Given an agent's beliefs and preferences, initiating or perpetuating conceptual conflict become appropriate means to chosen ends. Under such conditions, conceptual conflict is incentivized. When this occurs, the successful implementation of ameliorative projects becomes considerably more difficult.

In a sense, existing worries about lack of control, while not false, underdescribe the practical hurdles facing conceptual engineers. To be sure, we can't easily control the relevant metasemantic facts. But just as important is the fact that we can't easily control the behavior of other agents, some of whom will have good reason to oppose our ameliorative projects. ${ }^{3}$ To the extent that ameliorative projects require the coordination of potentially large numbers of agents, then, we will in many cases face a serious practical problem. Instead of coordination, we'll encounter conflict, brought about by the purposive action of agents rationally responding to incentives.

\footnotetext{
${ }^{3}$ Of course, we lack control over agents who oppose us regardless of whether metasemantic externalism is true. Accordingly, claims about the extent to which internalist metasemantic theories render conceptual engineering much simpler - as in Burgess \& Plunkett (2013) - are overstated.
} 
We can think of the relationship between incentives and conceptual conflict in the following schematic way. Roughly, there are two main ways in which conceptual conflict becomes rational. According to the first, agents with conflicting preferences and/or beliefs clash over the expected downstream effects of successfully implementing an ameliorative proposal. When agents have conflicting preferences about the desirability of these downstream effects, conceptual conflict becomes incentivized as a means to secure their preferred outcome, whether a maintenance of the status quo or the implementation of an opposing ameliorative proposal with different expected downstream effects. ${ }^{4}$ According to the second, an agent (or group of agents) might be able to secure benefits from initiating conceptual conflict. Simply by initiating conflict, such agents can secure benefits, even if no benefits come from the downstream effects of securing one ameliorative proposal over another.

Naturally, cases of rational conceptual conflict involving more complex mixed motivations are possible. Within the same conflict, some agents might be motivated by the prospective gain rendered likely by implementing their preferred ameliorative proposal, while others might initiate conflict simply because the conflict itself yields rewards. In some cases, there may be benefits both to securing a preferred ameliorative proposal and to initiating the conflict itself. Regardless of the underlying motivations, however, rational conceptual conflict plausibly presents a problem for the implementation of ameliorative proposals.

However, one might be skeptical of the severity of the problem posed by rational conceptual conflict. A preliminary worry concerns the degree to which this description of conceptual engineering and conceptual conflict over-intellectualizes typical concept-involving

\footnotetext{
${ }^{4}$ We can make a further distinction between cases where the relevant agents (dis)value the downstream effects noninstrumentally and cases where the relevant agents (dis)value the downstream effects instrumentally (i.e., to secure some independently valued end).
} 
behavior. ${ }^{5}$ How we acquire and subsequently use concepts, one might think, does not depend on overt intentions to acquire and use concepts, in much the same way that linguistic conventions can arise as solutions to recurrent coordination problems without any deliberate attempts to create and sustain such conventions (Lewis, 1969). Similarly, conceptual change that arises as the aggregate result of repeated interaction among groups of agents is not something any agent intends. Conceptual change, while an outcome of human action, is not a product of human design (Keller, 1994). Purposive action involving underlying motivations (and thus incentives) doesn't feature in such processes. Why think, then, that conceptual engineers will face resistance from agents with explicit intentions to impede their efforts?

However, while we should avoid over-intellectualizing such behavior, we should also avoid under-intellectualizing it. We can occasionally step back and reflect on our concepts, assaying their overall quality, even if most of these concepts have developed and been acquired as a result of largely unreflective processes. Concept-involving behavior is no different to other forms of behavior insofar as it can fall along a spectrum ranging from the unreflective and more-or-less automatic to the deliberate, intentional, reflective, strategic, and so forth. Walking, for instance, is typically automatic. But sometimes, as when we traverse rough terrain, we pay attention to where and how we walk. Sometimes we even walk in unison, engaging in deliberate forms of collective action such as marching or protesting. So it goes with concept-involving behavior: sometimes it is entirely automatic, but sometimes we engage in higher-order thought about which concepts to use (and how to use them), attempt to identify conceptual lacunae, and more. Sometimes we even engage in sophisticated forms of collective action, such as when groups attempt to engineer concepts. And, of course, sometimes we engage in deliberate conceptual conflict.

\footnotetext{
${ }^{5}$ I thank an anonymous referee for pressing me to think more carefully about this issue.
} 
Another worry concerns the degree to which different ameliorative projects require the coordination of different agents. Perhaps in some cases conceptual engineers will be satisfied once their preferred ameliorative proposals are understood by sufficiently many other agents, even if these agents do not go on to use the relevant concepts in ways urged by the ameliorative proposals. Such endeavors would mostly do away with ameliorative projects (understood as concrete efforts to bring about actual conceptual change), thereby rendering unnecessary the need for coordination among large groups of agents. If such projects in conceptual engineering exist, rational conceptual conflict doesn't threaten them.

Still, it's clear that there are many projects in conceptual engineering for which the coordination of often large numbers of agents is indeed a requirement. For instance, consider Robin Dembroff's efforts to "engineer a revised concept [of sexual orientation] ...in light of particular theoretical and socio-political purposes" (Dembroff, 2016: 2). For another, consider Sally Haslanger's accounts of race and gender, crafted with the intent to be "effective tools in the fight against injustice" (Haslanger, 2000: 36). ${ }^{6}$ These sort of ameliorative projects, explicitly undertaken with ambitious political aims in mind, will not be successful without the coordination of potentially exceptionally large numbers of agents.

More obviously, consider efforts to engineer a concept such as MARRIAGE such that it becomes more inclusive and less discriminatory by permitting marriage between same-sex couples (Ludlow, 2016: 22-3; Pollock, 2019). ${ }^{7}$ For such an ameliorative project to succeed, the coordination (and indeed deliberate cooperation) of many agents is a requirement, especially

\footnotetext{
${ }^{6}$ See also Kate Manne's ameliorative account of misogyny (Manne, 2018: 55-77).

${ }^{7}$ When discussing concepts, I use caps. When discussing word-meanings, I use single quotation marks. So, one can attempt to engineer the concept of MARRIAGE, but one can also attempt to change the meaning of the word 'marriage'.
} 
agents in institutional settings with the power to shape legislative language. At least some projects in conceptual engineering, then, require the coordination of many different agents.

Lastly, one might be skeptical of the claim that rational conceptual conflict presents a serious problem, even if many ameliorative projects require the coordination of large numbers of agents. First, one might think that conceptual conflict is not incentivized in sufficiently many contexts for it to constitute a pressing practical problem for conceptual engineering. However, such skepticism is implausible. In fact, the sort of incentives which drive conceptual conflict are quite common. As we'll see in the following section, there are at least three kinds of incentives that drive such conflict: material incentives, social incentives, and moral incentives. Moral incentives to engage in conceptual conflict, for example, appear whenever conceptual disputes involve agents who disagree about related moral issues. Under such conditions, the expectation should be that some level of rational conceptual conflict will occur, with the underlying moral disagreement driving the conceptual disagreement. Similarly, opportunities to boost one's social status by initiating or sustaining conceptual conflict are commonplace. For instance, everyday conceptual disputes regarding important political concepts are often divided along partisan lines. ${ }^{8}$ When disputes are divided along partisan lines, social incentives to engage in conceptual conflict are present. Since partisanship and political conflict are common, the relevant incentives are also common..$^{9}$ Lastly, there are material incentives to engage in conceptual engineering of important legal concepts, for example, whenever there is competition over legal language among interest groups. Since these incentives are common, it's implausible to maintain that rational conceptual conflict is rare.

\footnotetext{
${ }^{8}$ For instance, see Smith (2020) for discussion of how Americans who support different political parties have often different ideas about which sorts of policies are socialist.

${ }^{9}$ The nature of these social incentives will be explored in greater detail in section 2.2.
} 
Second, one might grant that rational conceptual conflict is not a rare phenomenon while still maintaining that a large class of ameliorative projects remain feasible. Not all ameliorative projects require coordination among burdensome numbers of agents. Some conceptual engineers may have more modest ambitions, content to secure conceptual coordination in conversational settings with low numbers of participants (Pinder, 2019; Jorem, forthcoming). To the extent that these more modest projects are insulated from incentives that drive conflict, some projects in conceptual engineering are not subject to the problem outlined in this paper.

Conceptual engineers stressing the importance of these sorts of projects are correct to note that they are simpler than more ambitious, large-scale projects. Intuitively, the lower numbers involved renders implementation more easily achievable. Moreover, there is some empirical evidence that novel conceptual coordination in conversations is relatively easy to achieve in certain conditions (Garrod \& Anderson, 1987; Garrod \& Doherty, 1994; Brennan \& Clark, 1996; Garrod \& Pickering, 2004). We should, however, avoid generalizing too much from these studies. Conceptual coordination is often actively incentivized in these studies by furnishing participants with a common purpose - for instance, the joint navigation of a maze (Garrod \& Anderson, 1987; Garrod \& Doherty, 1994). Additionally, participants in these studies do not stand to gain by defecting from coordination. However, in some settings in which ameliorative projects are undertaken, coordination will be disincentivized and conflict incentivized. This is true even of modest ameliorative projects involving low numbers of agents. With the relevant incentives in place, we shouldn't underestimate the difficulties of securing conceptual alignment even in those ameliorative projects that are putatively the simplest to achieve success in. I conclude, then, that rational conceptual conflict poses a serious practical problem for conceptual engineers. 


\section{Case Studies in Rational Conceptual Conflict}

Conceptual conflict is bred by a wide variety of incentives in many different contexts. In this section I discuss several examples of rational conceptual conflict, focusing on cases driven by material incentives, social incentives, and moral incentives.

\subsection{Material Incentives}

Sometimes the downstream effects of competing ameliorative proposals are such that, given agents with competing beliefs and preferences, material incentives to engage in conceptual conflict emerge. This is most obvious in cases of institutionalized conceptual engineering - that is, conceptual engineering as it occurs in legal and political institutions (Cappelen, 2018: 36).

Consider recent disputes over the legal definition of 'burger', 'hot dog', and other related expressions. ${ }^{10}$ Legislators in Mississippi recently passed a law which precludes manufacturers of plant-based products from using expressions like 'veggie burger' or 'vegan hot dog'. Instead, expressions like 'burger' and 'hot dog' are to be reserved for products derived directly from livestock. The legislation has been justified on the grounds that it serves to prevent consumer confusion. However, members of various plant-based industries claim that this justification is spurious. The real purpose of the law, they claim, is to protect traditional farming industries from competition.

Similar disputes have arisen over the legal definition of 'milk'. Scott Gottlieb, former commissioner of the US Food and Drug Administration, has advocated restricting usage of the expression 'milk' to traditional dairy milk, banning its application to various plant-based products derived from oats, soy, almonds, and more (Gibson, 2018). Again, while the nominal justification

\footnotetext{
${ }^{10}$ See Piper (2019) for relevant discussion.
} 
of such a ban is consumer protection, members of the relevant plant-based industries view this as an instance of attempted regulatory capture. As they see it, members of the meat industry have effectively co-opted the regulatory process to further their pecuniary interests.

These are cases where the downstream effects of adopting a given ameliorative proposal are such that one group will benefit greatly while another bears some costs. Members of traditional agribusiness industries stand to benefit financially if competitors are prevented from marketing their products in ways that maximize their appeal. Correlatively, members of plant-based industries stand to lose from the downstream effects of implementing the relevant ameliorative proposals. The differential expected benefits and expected costs incentivize both groups to engage in conflict over the relevant legal language. To maximize their chances of winning the conflict, each group is further incentivized to adopt various strategies to successfully implement their preferred proposal. In legal cases such as this, such strategies might involve establishing a channel of communication with (and influence over) appropriate legislative bodies. Without such influence, it's unclear how their preferred proposals would be implemented.

However, conflict in institutionalized conceptual engineering is not always undertaken with the pursuit of wealth in mind. More insidious material incentives are often present. Consider disputes over the legal definition of 'torture' (Skolnick, 2004; Posner, 2004; Griffin, 2010). Legal prohibitions against torture prevent authorities from using methods of interrogation like waterboarding against either domestic citizens or foreign nationals. But the legal definition of 'torture' is malleable. Those seeking to deploy currently prohibited methods of interrogation are incentivized to bend active definitions to their purposes. With the appropriate definition of 'torture' in place, practices such as waterboarding become legally available to those willing and able to 
deploy them. The more effective social control afforded by such practices offer powerful material incentives (Coyne and Harris, 2018: Ch. 7).

Notably, though, we should expect attempts to widen the legal definition of 'torture' to be vociferously opposed by various groups. Perhaps such groups do not want greater amounts of power (in the form of more effective methods of social control) to become available to agents of the state. Perhaps such groups oppose the proposed changes on distinctively moral grounds. ${ }^{11}$ Those who seek to capture legal language to increase their power often possess very different motivations from those who oppose them. Regardless, conflict between such groups is rational, driven by conflicting attitudes towards the downstream effects of implementing a given ameliorative proposal.

Cases of conceptual conflict driven by material incentives need not occur in formal, institutionalized settings. Consider an interest group that advocates a controversial set of institutional reforms - the replacement of elections as mechanisms for selecting political representatives with lotteries, for example (Guerrero, 2014). Such an interest group may choose to market their proposals as democratic, even if extant conceptions of democracy generally tie democracy to the use of regular, free, and fair elections. In effect, the interest group attempts to broaden the concept of DEMOCRACY in order to exploit its positive connotations (Pincione \& Tesón, 2006: 44-5). ${ }^{12}$ Predictably, however, interest groups with opposing agendas will attempt to prevent the concept of democracy from becoming widened. One might even imagine political representatives with a vested interest in maintaining the electoral system opposing the relevant

\footnotetext{
${ }^{11}$ Potential conflict between material and moral incentives is explored further in Section 2.3.

${ }^{12}$ To be clear, proponents of sortition can rightly claim that historical accounts of democracy recognized lotteries as legitimately democratic selection mechanisms. The point, though, is that contemporary accounts often ignore this historical pedigree, and, at some point, popular concepts of democracy shifted towards including the use of elections as a necessary condition of any democracy. Accordingly, proposals to widen the concept to once more recognize the democratic legitimacy of lotteries are rightly views as ameliorative proposals.
} 
ameliorative proposal. These representatives, in an effort to maintain their political position, together with all the privileges it accords them, possess powerful material incentives to engage in conceptual conflict.

\subsection{Social Incentives}

The above cases mostly take place in institutional settings and are driven by the prospect of material gain. As the last case demonstrates, though, rational conceptual conflict can occur outside of legislative contexts. Departing even further from such cases, incentives to engage in conceptual conflict are not always straightforwardly material. Much quotidian communication reveals a pattern of reward-seeking behavior wherein agents seek social benefits such as esteem, praise, and increased social status. ${ }^{13}$ Notably, such behavior frequently involves the deliberate initiation of conceptual conflict. Through the initiation of conceptual conflict, agents can signal to others in ways that secure social benefits, impose social costs on ideologically opposed peers, or both.

Why might this happen? Consider first a phenomenon like grandstanding. Grandstanding utterances are contributed to some public discussion with the aim of persuading others that the speaker is morally impressive in some respect (Tosi and Warmke, 2020: 15). For example, consider a group of people discussing the relative merits of various gun control policies. A consensus emerges, with the group favoring tighter restrictions. After much discussion, a previously quiet participant announces:

\footnotetext{
${ }^{13}$ The fact that social pressures often lead us to modify our communicative behavior has long been recognized. See Goffman (1967) for a classic account.
} 
(1) I just want to be clear that I fully support everything that has been said so far, and that I have always opposed lax gun control. ${ }^{14}$

In some cases, such an utterance is intended to signal to one's peers acceptance of the group's overall views on gun control. It is thus a way to maintain one's status within one's social group. Of course, such utterances can sometimes be sincere, non-status-seeking attempts to clarify the content of one's beliefs relative to the content of one's peers' beliefs. It can often be useful to make explicit one's considered views during heated political discussions. Still, in many cases such utterances are purely grandstanding.

Much like it incentivizes grandstanding, social esteem incentivizes agents to deliberately initiate conceptual conflict. In some cases, taking a stand on one side of a conceptual dispute signals one's affiliation with a position, ideology, cause, and so on (Davies, forthcoming: 10-11). ${ }^{15}$ Not ceding any conceptual ground to one's ideological opponents can act as a signal to others regarding the sincerity of one's beliefs, enhancing the credibility and esteem of the speaker.

Consider the following sort of public exchange, perhaps in an online forum, which I take to be representative of large swathes of political discourse. Suppose Jack utters:

(1) I'm a socialist. I want to implement policies like those found in Scandinavian countries.

Suppose further that Jill responds with:

\footnotetext{
${ }^{14}$ See Tosi and Warmke (2016: 204) for a similar example.

${ }^{15}$ Note, though, that not all forms of the sort of identity display Davies investigates involve grandstanding. See Davies (forthcoming) for further discussion.
} 
(2) Scandinavian countries are not socialist. They are just market economies with some redistribution of wealth.

Let's say that Jack and Jill agree on all the basic facts about the structure and function of the relevant political and economic institutions, facts about the sorts of policies regularly implemented in Scandinavian countries, and the like. If there is a disagreement here, it seemingly concerns the concepts possessed by both, with each possessing a different concept of SOCIALISM. At this point, one might expect fully cooperative speakers to note the putative conceptual mismatch. Cooperative speakers might handle this mismatch by accommodating the other's usage of their preferred concept, or by agreeing to state their disagreement without reference to the contested concept (Chalmers, 2011). Sometimes, though, declining to cooperate yields social benefits for certain agents. In such cases, the prospect of social reward comes into tension with any tacit commitment to cooperative communication.

The conversation continues with Jack saying that:

(3) That's all I mean by 'socialist'.

Jill, though, spotting the opportunity to grandstand, simply replies with:

(4) That's not real socialism. Real socialism requires central planning of the economy. 
Let's suppose that Jill utters (4) because she knows it sends the right sort of message to her ideologically likeminded peers. ${ }^{16}$ In this case, then, the opportunity for a serious discussion on the respective costs and benefits of alternative institutional arrangements is passed up in favor of what I call conceptual grandstanding. Refusing to accommodate Jack's preferred concept allows Jill to signal to her peers her disapproval of the sort of policies Jack endorses. This, in turn, secures or boosts Jill's status within her political in-group. Conversely, acts of conceptual accommodation to ideological opponents might be penalized by one's in-group. If that's right, reasonable discussions with agents who possess opposing viewpoints are actively disincentivized. One might even think that the simple act of disrespecting Jack (by tersely dismissing his attempt to clarify which concept of socialism he possesses) is itself a benefit for Jill. In a social environment bristling with hostility towards one's political opponents and full of partisan bickering, such acts of hostility are often the preferred course of action for deeply partisan agents. ${ }^{17}$ Conceptual mismatches, affording the ability to initiate conceptual conflict, are just one method among many of insulting, mocking, or otherwise disrespecting one's political opponents.

Unlike our earlier cases of institutionalized conceptual conflict, the goal of conceptual grandstanding is not to attain some goods by successfully implementing a given ameliorative proposal that will, in expectation, result in desirable downstream consequences. The goal is to secure benefits by the mere initiation of conflict itself. The conflict is still a means to an end, but the end can be brought about regardless of whether implementation is achieved. Indeed, one can easily imagine cases where speakers initiate conceptual conflicts while otherwise believing that

\footnotetext{
${ }^{16}$ Of course, not every utterance like (4) constitutes an attempt to grandstand. In other settings, for instance, such an utterance might be used to sincerely express one's conviction that concepts of socialism requiring central planning are in some sense superior. Or perhaps one insists on a certain way of using a concept to avoid having one's views misrepresented. In general, token utterances of the same sentence type can be used to grandstand on some occasions of use while used for non-grandstanding purposes on others.

${ }^{17}$ See Mason (2018) for an insightful discussion of how political ideology intersects with issues of identity.
} 
the concept one is advocating for is unreasonable, or while simply not caring whether one's concept is a good or useful one to be using. Such cases involve social incentives overriding our more considered philosophical judgement.

It's natural to focus on settings involving partisanship and contentious political disputes when considering social incentives to engage in conceptual conflict. But it's worth observing that similar social incentives are present in other contexts too, including contexts where one might otherwise think that agents are less easily swayed by social pressures. Consider, for example, the incentives an academic philosopher sometimes faces when deciding what work to submit to professional journals. All else being equal, suppose that more exciting, more provocative work maximizes one's chances of securing publications, and that a great number of publications in top journals maximizes one's chances of securing a host of other career-related benefits, ranging from the esteem of one's colleagues to greater job prospects. Such mixed material and social incentives might indirectly drive philosophers to, for example, advocate for controversial ameliorative proposals that strike the right balance between generating excitement, novelty, and - one would hope - plausibility. Alternatively, such incentives may influence some to willingly adopt critical stances of existing work where they would otherwise be less bullish. Staking out a controversial position against well-established figures can be an effective way to secure professional and social rewards. In turn, these controversial and exciting positions can themselves become the focus of prospective publications, with other academics pursuing the same sorts of professional and social benefits. By such means might conceptual disputes among professional philosophers be both created and sustained. ${ }^{18}$

\footnotetext{
${ }^{18}$ I return to this point in the final section, as well as addressing some complications regarding the potential benefits
} of conflict in academic research. 


\subsection{Moral Incentives}

Before moving on to consider some important methodological implications of rational conceptual conflict, one further set of incentives to engage in conceptual conflict - moral incentives - warrants discussion. While some agents engage in conceptual conflict to secure material or social benefits, others engage in it because they think it is the right thing to do. For instance, they may see what they think of as other agents engineering (or attempting to engineer) concepts in morally incorrect ways and, in order to prevent the implementation of morally incorrect ameliorative proposals, they engage in conceptual conflict. More generally, they might identify existing perceived conceptual injustices, engaging in conflict in an attempt to rectify them.

Consider, again, our earlier discussion of torture. We saw that some agents might be incentivized to capture the relevant law to engineer the concept in such a way that waterboarding does not, for legal purposes, constitute torture. Such agents possess material incentives of a sort; they are motivated by the acquisition of power and tools of social control. Their opponents, however, may be opposed simply because they think waterboarding is immoral. Nobody ought to waterboard anybody, and so waterboarding should not be legal. ${ }^{19}$ Such agents possess obvious moral incentives to engage in conceptual conflict with those who wish to engineer the concept of TORTURE such that waterboarding is not torture. Additionally, consider the activities of conceptual engineers themselves. Those who are motivated by a desire to right what they view as existing conceptual injustices are clearly driven by moral incentives of a sort. When conflict is necessary to achieve their aims, conceptual engineers are often the ones who deliberately initiate conceptual conflict. Indeed, those with whom they quarrel may often be other conceptual

\footnotetext{
${ }^{19}$ Of course, not everything that is immoral is - or should be - illegal. Accordingly, from the fact that something is immoral one cannot conclude that something ought to be illegal. People opposed to the legality of waterboarding would therefore need additional support for their stance, though one can imagine that such support is easy to attain.
} 
engineers, similarly driven by their own sincere underlying moral commitments. In these cases, conflict is both a means to securing to implementation and an obstacle to securing implementation.

The effects of moral incentives on conceptual disputes are more widely recognized than those of material or social incentives. Nonetheless, certain facts about these incentives should be borne in mind by putative conceptual engineers. First, very many conceptual disputes intersect with precisely the sort of substantive moral issues that drive conceptual conflict. Consider disputes about concepts such as PERSON, MARRIAGE, CAPITALISM, SOCIALISM, RACE, GENDER, DEMOCRACY, FREEDOM, JUSTICE, and more. In order to secure one's preferred ameliorative proposal regarding any one of these concepts, one will likely encounter sustained and vigorous opposition from agents with opposing values.

Second, high-stakes ameliorative proposals involving important social and political concepts are more likely to involve pervasive moral disagreement than low-stakes ameliorative proposals involving less important concepts. Indeed, efforts to engineer various social and political concepts are often seen as important because they are driven by our underlying values. But this suggests that conceptual engineering will increase in difficulty as it becomes more important, in part because the likelihood that we encounter resistance from agents with opposing moral incentives increases.

Lastly, it would be premature to assume that the difficulties created by misaligned moral incentives could be avoided by appealing to putatively objective moral facts which, in some sense, settle the relevant disputes. ${ }^{20}$ Setting aside obvious controversies regarding the existence of objective moral facts, even if such facts exist, they may not help avoid conceptual conflict whatsoever. It could very well be the case that, for any given conceptual dispute, one side is

${ }^{20}$ C.f. Plunkett's remarks on the connection between disputes in conceptual ethics and the existence of objective normative facts (Plunkett, 2015: 860-1). 
objectively correct about the extent to which their preferred ameliorative proposal aligns with objective moral facts. It could even be the case that one side of a dispute is behaving in an obviously epistemically and morally irresponsible fashion. Still, that is true of any dispute, and disputes persist nonetheless. Moral disagreement, even if utterly misguided, is enough to create and sustain conceptual conflict.

In addition to material and social incentives, then, moral incentives constitute an important source of conceptual conflict. Widespread moral disagreement impedes the implementation of ameliorative proposals. Moral disagreement, along with other sources of conceptual conflict, presents an interesting and important practical problem for conceptual engineers.

\section{Methodological Implications of Rational Conceptual Conflict}

We've seen that rational conceptual conflict occurs in many different contexts, driven by a wide variety of incentives. Such conflict raises serious difficulties for many important projects in conceptual engineering. Naturally, this has important methodological consequences for conceptual engineers, both negative and positive. Let's examine each in turn.

Negatively, the difficulties created by rational conceptual conflict will in certain cases militate entirely against embarking on ameliorative projects. First, in some cases conflict will constitute such a serious obstacle that it effectively renders the successful implementation of an ameliorative proposal impossible. If so, then it's plausible to suppose that conceptual engineers shouldn't waste their time with such futile endeavors, especially in cases where the conflict has its own costs.

Consider again our earlier example involving attempts to engineer the concept of DEMOCRACY such that the use of lotteries to select political representatives counts as legitimately 
democratic. Suppose that proponents of lotteries face considerable levels of opposition. Competing interest groups, as well as the overwhelming majority of the general public, find their proposals unintuitive and implausible. Worse still, their ameliorative proposals garner significant backlash, seen by many as attempts to delegitimize and destabilize valuable democratic institutions. Proponents of these proposals are vilified, eventually bearing many costs, both personal and professional. If, due to widespread opposition, implementation of the relevant ameliorative proposal is impossible, and if, due to the vilification they receive, proponents of lotteries bear steep costs and comparatively few (if any) benefits, it seems that they should, prudentially speaking, avoid attempting to implement their proposals entirely. Their time and energy are better put towards alternative ends.

With that said, at least two important caveats should be noted. On the one hand, in some cases there may be good reason to attempt to implement one's preferred proposal even if one knows that one's likelihood of success is nil. Perhaps some good can come of the attempt itself, even if one's ultimate aims are frustrated. For instance, imagine that proponents of lotteries are content to spread awareness of their proposals, even though they're aware of their dim prospects for success. As things stand, they will not succeed, but their efforts today lay the groundwork for future proponents who may fare better. On the other hand, in cases where those who deliberately impede our ameliorative projects act unjustly, it might be intrinsically good to resist their injustices, even if our likelihood of success is nil and even if no downstream instrumental benefits arise from the attempt itself. Recall the earlier suggestion that elected representatives with a vested interest in maintaining the status quo would oppose such ameliorative reforms. Suppose that these representatives have good reason to believe that the relevant ameliorative proposals offer an allthings-considered better concept of DEMOCRACY. Suppose further that the sort of institutional 
reforms proponents of lotteries endorse would greatly improve on existing institutions, improving the lives of virtually everybody. Nonetheless, representatives block the proposed reforms, both conceptual and institutional, in order to maintain their privileged position. If so, their recalcitrance is unjust. In such a case, conceptual engineers, doomed to failure due to the unjust actions of others, may have reason to attempt implementation regardless. If nothing else, such behavior is a symbolic act of resistance.

Second, the expected costs of the conflict may simply outweigh the aggregate expected benefits of both implementing the relevant proposal and any subsidiary benefits that arise from merely attempting to implement it, even if those benefits are non-zero. For example, if the expected benefits of implementation are both relatively low and improbable, while the expected costs of conflict are both relatively high and likely to occur, this suggests that conceptual engineers should refrain from the attempt altogether. To continue the preceding example, suppose that the benefits of engineering the concept DEMOCRACY such that lotteries are genuinely democratic selection mechanisms are slight - proponents of this proposal, as well as ordinary citizens unconcerned with such matters, would not gain very much, if anything. Suppose moreover that there is a considerable degree of uncertainty whether the ameliorative proposal in question can even be feasibly implemented. $^{21}$ If, in contrast, the putative conceptual engineers could confidently predict significant amounts of very costly conflict, this suggests that they should refrain from the attempt entirely (bearing in mind, naturally, the two caveats outlined previously).

Of course, the costs of conflict will not always be high enough to militate against attempting to engineer concepts. In cases where the expected benefits outweigh the expected costs,

\footnotetext{
${ }^{21}$ Of course, the very same points might apply to the associated institutional proposals themselves; that is, the benefits of transitioning from electoral democracy to the use of lotteries as selection mechanisms may be slight (if there are any at all), and the reforms may not be feasibly implementable. On the former point, see Landa and Pevnick (2021).
} 
it is rational for putative engineers to pursue their ends, even in cases where the probability of success is low. ${ }^{22}$ Such a case would arise if, for example, the probability of successfully engineering the concept DEMOCRACY was low, but the expected benefits from implementation were sufficiently great. Still, conceptual engineers should factor expected costs of conflict into their decisions about whether to pursue ameliorative projects. On occasion, these costs will be great enough to count against such pursuits entirely.

However, in addition to some negative implications, there are positive upshots to the recognition that conceptual conflict is driven by incentives. First, a simple but important point: by knowing in advance the sort of contexts within which conceptual conflict is incentivized, conceptual engineers can more sagaciously choose which ameliorative projects to focus their efforts on. All else being equal, those projects which will predictably face protracted bouts of active resistance or sabotage from rational agents pursuing their own ends are less preferable to cases where conflict is either less likely or, even if likely, less likely to constitute a serious barrier to implementation. Consequently, conceptual engineers should, if possible, avoid attempting to implement ameliorative proposals in settings where incentives to engage in conceptual conflict are present. If this is too difficult, then settings where the relevant incentives are relatively weak are worth considering. After all, effectively disseminating a novel ameliorative proposal, overcoming comprehension deficits, and aligning the behavior of large numbers of agents are already difficult tasks. The presence of conflict merely compounds such difficulties.

Naturally, though, all else is not always equal, and the expected benefits of implementation are once more relevant. Roughly speaking, ameliorative projects with high expected benefits may be worth pursuing even if implementation must be attempted in contexts characteristically beset

\footnotetext{
${ }^{22}$ See Andow (forthcoming) for insightful discussion of the relevant issues.
} 
by conflict. Nonetheless, the presence of likely conflict might act as a tiebreaker in cases where different course of action would yield approximately the same expected benefits, with higher expected costs of conflict counting against proposals where conflict is expected to arise. More generally, the expected costs of conflict will be relevant when conceptual engineers are deciding between ameliorative projects with different quantities of expected benefits. Even if one proposal offers lower benefits than another, it might still be worth pursuing if it is significantly easier to implement as a result of encountering less resistance. ${ }^{23}$ In short, an accurate assessment of the potential costs of encountering rational conceptual conflict will help conceptual engineers to make better decisions about which ameliorative projects are worth pursuing; and to make these more accurate assessments, knowledge of the conditions under which conceptual conflict is incentivized is crucial.

In this vein, it might be helpful for conceptual engineers to empirically investigate such matters. Perhaps certain types of concepts are subject to more conflict than others. For instance, perhaps efforts to engineer socio-political concepts will encounter more conflict than efforts to engineer scientific concepts. Perhaps certain strategies to secure implementation have a better track record than others. We could examine various attempts to, say, secure implementation for novel ameliorative proposals in institutional settings in order to determine which methods deployed by the relevant conceptual engineers are more effective. Perhaps, for instance, strategies that seek incremental adjustments of existing concepts are typically more successful than those seeking significant conceptual revision or conceptual abandonment.

Let's now consider a second positive implication, the importance of which is neglected: recognizing the fact that incentives play a crucial role in driving conceptual conflict will allow

\footnotetext{
${ }^{23}$ Indeed, this point generalizes. All else being equal, ameliorative proposals that face fewer practical impediments of any kind are preferable to those facing more practical impediments.
} 
conceptual engineers to develop more effective strategies for implementing their ameliorative proposals. As we've seen, the background context within which ameliorative projects are pursued is important. In some settings, incentives to engage in conceptual conflict will be common and powerful; in others, coordination and cooperation will be incentivized. Crucially, though, we can deliberately alter the background context in order to modify the payoffs and penalties associated with cooperative behavior. In a slogan: engineer the social environment to better engineer the concepts.

Indirect strategies that attempt to modify existing incentives may be more effective than direct strategies that ignore underlying incentives, holding fixed the background context, while attempting to influence agents within that context. Consider first a direct strategy. In recent work, Rachel Sterken suggests that a particular sort of linguistic intervention can disrupt established patterns of concept use in such a way that concept users become more amenable to accepting novel ameliorative proposals (Sterken, 2020). ${ }^{24}$ Sterken calls successful interventions in this vein transformative communicative disruptions - so called because they prompt a transformation on the part of the target agent's understanding of the relevant concept (Ibid, 430).

How might these linguistic interventions work? Suppose an agent wants to engineer a concept by implementing a given ameliorative proposal. Let's suppose the concept is PERSON, and that the proposal in question would classify as persons all sorts of non-human animals, including regular household pets, animals traditionally kept as livestock, and more. One way for the putative conceptual engineer to proceed is to use the concept as if it already had the meaning it would have post-amelioration, and to interpret other concept users as if they are using the concept in ways that align with the ameliorative proposal in question. For instance, if asked about the

\footnotetext{
${ }^{24}$ See also Cantalamessa (2019) for relevant discussion.
} 
kindest person they know, they could mention their pet gerbil. The rationale behind such a communicative act is to prompt reflection on the target concept in one's audience. If the agent attempting the intervention is typically serious, or is known to hold strongly anti-speciesist views, the target might begin to wonder what the agent is trying to communicate. Perhaps with subsequent reflection comes acknowledgement of the various defects our concept of PERSON possesses (if it is indeed defective); and perhaps with such acknowledgement comes amenability to adopting ameliorative proposals designed to remedy those defects.

However, claims about the purported benefits of disruptive linguistic interventions rest upon some contentious empirical assumptions. On the one hand, it's unclear whether disrupting standard communicative patterns by using concepts in highly non-standard ways will cause one's intended audience to engage in the sort of reflection the process needs. Disruptive, uncooperative communication may simply lead to confusion, frustration, or even annoyance (Garfinkel, 1967: 42). ${ }^{25}$ On the other hand, even if reflection is prompted, people who attempt these sorts of linguistic interventions also need to navigate a social environment in part constituted by agents with competing beliefs, preferences, and - very often - misaligned incentives. Importantly, however, linguistic interventions by themselves do not shift the background incentives in such a way that conflict becomes disincentivized.

In cases like the above, other agents may oppose the relevant ameliorative proposal on moral grounds, perhaps because they believe that most (or even all) non-humans cannot be persons. Alternatively, if the attempted intervention occurs in a context that affords grandstanding, the process can be derailed by agents who seek to benefit socially from publicly airing their

\footnotetext{
${ }^{25}$ See Stokoe (2018: 44-5) for further discussion.
} 
opposing views. ${ }^{26}$ Failure of linguistic intervention can also occur in cases with alignment of preferences but misalignment of beliefs. The audience might agree that the relevant concept ought to be ameliorated while also thinking that linguistic interventions are too unreliable to effectively secure implementation. If such agents believe that more effective means are available, they may intentionally decline to coordinate with the speaker attempting the linguistic intervention. In short, both conflicting values and conflicting beliefs about the appropriate way to secure implementation for ameliorative proposals can incentivize rational conceptual conflict, even when linguistic interventions are attempted.

Of course, I do not claim that linguistic interventions can never succeed; nor do I claim that direct strategies more generally will always fail. With that said, we should be realistic about the difficulties direct strategies will face in environments where misaligned incentives pull agents in opposing directions. ${ }^{27}$ At the very least, it is advisable to pursue direct strategies in tandem with indirect strategies that attempt to modify background incentives.

Let's now consider an indirect strategy. Recall the possibility that protracted bouts of conceptual conflict might be incentivized within academic philosophy because more controversial and more combative manuscripts with bold ameliorative proposals are more likely to be published, more likely to gain the esteem of one's peers, and more likely to gain their author professional notoriety than less controversial and more conciliatory manuscripts displaying a higher willingness to attempt conceptual rapprochement. ${ }^{28}$ Making headway on longstanding conceptual disputes

\footnotetext{
${ }^{26}$ Admittedly, there may also be cases where the opportunity to grandstand is most naturally expressed by publicly accepting the novel ameliorative proposal.

${ }^{27}$ Koch (2018) argues that we can exert a certain degree of long-range collective control over our concepts. For reasons that should be clear, though, I think this claim is overly optimistic. Rational conceptual conflict will, in most cases, render such control extremely difficult to maintain (even setting aside the difficulties of coordinating large numbers of non-conflicting agents separated from each other in space and time, as well as other practical worries).

${ }^{28}$ This likely oversimplifies the landscape of incentives facing academic philosophers seeking to publish in reputable journals. It's possible that the range of acceptable views is constrained by an academic Overton window of sorts, and that controversial and combative views falling outside this window do not deliver professional benefits to those
} 
might require a greater willingness to engage in collaborative work, where philosophers who are otherwise sharply opposed to one another can set aside their differences and attempt to compromise on mutually acceptable ameliorative proposals. If so, then we should strive to cultivate professional institutional settings where such cooperative enterprise is rewarded as much as more antagonistic work.

To achieve this, there are several things academic philosophers could do. For example, journals could devote special issues to the (potential) resolution of persistent conceptual disputes that arise among philosophers, whether historically speaking or among contemporary philosophers. Similarly, conferences could revolve around themes related to conceptual collaboration, the reconciliation of seemingly opposing views, and so on. The idea here is relatively straightforward: conference presentations, publications, and their downstream benefits (disciplinary esteem, citations, tenure, and so on) are the rewards philosophers pursue, and given existing incentives, they frequently pursue them with bold, controversial work that perpetuates existing conflicts. But if the very same rewards could be achieved by work that attempts to resolve conflict, then we could incentivize greater levels of (conceptual) collaboration.

With that said, I am not claiming that we should eliminate conceptual conflict entirely. Valuable research can be produced by people intentionally staking out a controversial position against salient academics. Sometimes conflict will be necessary to change concepts in desirable ways. More generally, a certain amount of conflict can be a good thing for reliable group inquiry (Zollman, 2010; Peters, 2020). ${ }^{29}$ Nevertheless, it may be that we fail to strike the right balance

academics willing to attempt to publish them. This, though, is consistent with bolder and more controversial work within this window being more easily published than more collaborative but less striking work. If so, the incentives still push philosophers to engage in conceptual conflict more than they would otherwise, even if by less than we initially assumed.

${ }^{29}$ See also Davies (2013) for related discussion. 
between incentivizing bold, original, occasionally combative work and incentivizing more cooperative work. At the very least, we could experiment with different indirect strategies, each shifting background incentives in different directions and to different degrees, in order to determine which enables the optimal balance between combativeness and collaboration.

Outside of the narrow confines of academic philosophy, feasible incentive alignment strategies will be harder to come by. Much conceptual engineering is attempted not within cloistered academic environments, but within the broader political community. Attempting to align the material, social, and moral incentives of this much wider class of agents is as ambitious as the very ameliorative projects indirect strategies seek to better enable, if not more ambitious. Still, like conceptual engineering itself, even if it is difficult, it is not impossible. And bearing in mind the complications noted above regarding the occasional benefits of conflict, the expected benefits of engineering our social environment to better enable fruitful conceptual cooperation may be high enough to render this endeavor worthwhile, even if the probability of success is low.

As with conceptual engineering itself, the expected costs and expected benefits will vary depending on the details. For instance, an attempt to engineer legal and political institutions to prevent interest groups from unduly influencing important legal language, even if possible, may be far too difficult. Even if it is achievable, preventing interest groups from shaping legal language may harm the activities of interest groups who set out to implement worthwhile and beneficial ameliorative proposals. Accordingly, this sort of undertaking should not be pursued lightly, as the expected costs may easily outweigh the expected benefits. Less ambitious endeavors, such as aligning the incentives of academic philosophers, are much less costly to pursue, while also offering the possibility of moving past stubborn philosophical disputes that resist resolution. At 
minimum, the prospect of beneficial indirect strategies should be explored by conceptual engineers.

\section{Conclusion}

Conceptual engineers must attend to the obstacles they are likely to encounter when attempting to implement their preferred ameliorative proposals. Among these obstacles are the activities of agents who are incentivized to oppose their ameliorative projects, whether in pursuit of material goods, in the hopes of boosting their social status, or because they are driven by substantive underlying moral commitments. Though this sort of conflict doesn't render successful conceptual engineering impossible, it is indeed a serious problem - the incentives that drive such conflict are common, they can harm the prospects of even relatively modest ameliorative projects, and practical measures to make ameliorative proposals easier to implement will likely fail if they ignore the underlying incentive structure which drives conflict in the first place. One pessimistic upshot of this paper is that the practical impediments created by rational conceptual conflict will sometimes be so severe that conceptual engineers should abandon their ameliorative proposals altogether.

At the same time, understanding that rational conceptual conflict is bred by incentives, together with knowing what those incentives are and in what contexts they commonly arise, can help conceptual engineers make better decisions about which ameliorative proposals to focus their efforts on. By knowing in advance the likely difficulties of pursuing projects in contexts where conceptual conflict is common, conceptual engineers can factor these costs into their decisions about which proposals to pursue. More ambitiously, conceptual engineers can begin to think about the possibility of engineering their social environment to better enable fruitful conceptual 
cooperation. By modifying the incentive structure in contexts where conflict would typically otherwise constitute a serious problem, conceptual engineers can make it easier for themselves to implement their proposals, incentivizing collaborative conduct and disincentivizing unproductive conceptual conflict. ${ }^{30}$

\section{References}

Andow, J. (forthcoming) Conceptual Engineering is unlikely to Work. So what? Inquiry: An Interdisciplinary Journal of Philosophy

Brennan, S.E. \& Clark, H.H. (1996) Conceptual Pacts and Lexical Choice in Conversation, Journal of Experimental Psychology: Learning, Memory, and Cognition, 22: 1482-93

Burgess, A. \& Plunkett, D. (2013) Conceptual Ethics I, Philosophy Compass, 8 (12): 1091-101

Cantalamessa, E. (2019) Disability Studies, Conceptual Engineering, and Conceptual Activism. Inquiry: An Interdisciplinary of Journal Philosophy, https://doi.org/10.1080/0020174X.2019.1658630

Cappelen, H. (2018) Fixing Language: An Essay on Conceptual Engineering. Oxford: Oxford University Press

Cappelen, H. \& Plunkett, D. (2020) A Guided Tour of Conceptual Engineering and Conceptual Ethics. In H. Cappelen, D. Plunkett, \& A. Burgess (eds.), Conceptual Engineering and Conceptual Ethics (pp. 1-26). Oxford: Oxford University Press

Chalmers, D.J. (2011) Verbal Disputes, Philosophical Review 120 (4): 515-66

\footnotetext{
30 Thanks to Liz Camp, Andy Egan, Jimmy Goodrich, Alex Guerrero, Ting-an Lin, Meradjuddin Khan Oidermaa, Mark Pinder, David Plunkett, Mark Schroeder, and an anonymous referee for their helpful feedback on different versions of this paper.
} 
Coyne, C.J. \& Harris, A.R. (2018) Tyranny Comes Home: The Domestic Fate of U.S. Militarism. Stanford, CA: Stanford University Press

Davies, A. (2013) 'Kuhn on Incommensurability and Theory Choice', Studies in History and Philosophy of Science 44 (4): 571-79

Davies, A. (forthcoming) Identity Display: Another Motive for Metalinguistic Disagreement, Inquiry: An Interdisciplinary Journal of Philosophy

Dembroff, R. (2016) 'What is Sexual Orientation?', Philosopher's Imprint 16 (3): 1-27

Fischer, E. (2020) Conceptual Control: On the Feasibility of Conceptual Engineering, Inquiry: An Interdisciplinary Journal of Philosophy 1-29

Garfinkel, H. (1967) Studies in Ethnomethodology. Upper Saddle River, NJ: Prentice-Hall

Garrod, S., \& Anderson, A. (1987) Saying What you Mean in Dialogue: A Study in Conceptual and Semantic Coordination, Cognition 27: 181-218

Garrod, S., \& Doherty, G. (1994) Conversation, Coordination, and Convention: An Empirical Investigation of how Groups Establish Linguistic Conventions, Cognition 53: 181-285

Garrod, S., \& Pickering, M.J. (2004) Why is Conversation So Easy?, Trends in Cognitive Sciences 8 (1): 8-11

Gibson, K. (2018) Label change for plant-based 'milk' could boost dairy industry, CBS News, $\mathrm{URL}=\langle$ https://www.cbsnews.com/news/label-change-for-plant-based-milk-could-boost-dairyindustry/>

Goffman, E. (1967) Interaction Ritual: Essays on Face-to-Face Behavior. New York, NY: Anchor Books

Griffin, J. (2010) What Should We Do About Torture?. In N.A. Davis, R. Keshen, \& J. McMahan (eds.), Torture: A Collection (pp. 3-22). Oxford: Oxford University Press 
Guerrero A (2014) Against Elections: The Lottocratic Alternative. Philosophy and Public Affairs 42: $135-78$

Haslanger, S. (2000) 'Gender and Race': (What) Are They? (What) Do We Want Them to Be?', Nous, 34 (1): 31-55

Haslanger, S. (2012) Resisting Reality: Social Construction and Social Critique. Oxford: Oxford University Press

Jorem, S. (Forthcoming) Conceptual Engineering and the Implementation Problem, Inquiry: An Interdisciplinary Journal of Philosophy

Keller, R. (1994) On Language Change: The Invisible Hand in Language. New York, NY: Routledge

Koch, S. (2018) The Externalist Challenge to Conceptual Engineering, Synthese, https://doi.org/10.1007/s11229-018-02007-6

Landa, D. and Pevnick, R. (2021) 'Is Random Selection a Cure for the Ills of Electoral Representation?', Journal of Political Philosophy, 29 (1): 46-72

Lewis, D. (1969) Convention: A Philosophical Study. Cambridge, MA: Harvard University Press Ludlow, P. (2014) Living Words: Meaning Underdetermination and the Dynamic Lexicon. Oxford: Oxford University Press

Manne, K. (2018) Down Girl: The Logic of Misogyny. Oxford, UK: Oxford University Press Mason, L. (2018) Uncivil Agreement: How Politics Becomes Our Identity. Chicago, IL: University of Chicago Press

Peters, U. (2020) 'Illegitimate Values, Confirmation Bias, and Mandevillian Cognition in Science', British Journal of Philosophy of Science 0: 1-24 
Pincione, G. \& Tesón, F.R. (2006) Rational Choice and Democratic Deliberation: A Theory of Discourse Failure. New York, NY: Cambridge University Press

Pinder, M. (Forthcoming) Conceptual Engineering, Externalism, and Speaker Meaning, Mind Piper, K. (2019) Mississippi is forbidding grocery stores from calling veggie burgers 'veggie burgers', Vox, URL $=$ 〈https://www.vox.com/future-perfect/2019/7/3/20680731/mississippiveggie-burgers-illegal-meatlessmeat?fbclid=IwAR0hnjMzwzPp63CkaBuljxTo6GCTHBIXZNKQio5QfBw2-

\section{NyNS6bkN7ulbEw>}

Plunkett, D. (2015) Which Concept Should We Use? Metalinguistic Negotiations and the Methodology of Philosophy, Inquiry: An Interdisciplinary Journal of Philosophy 58 (7-8): 828-74 Pollock, J. (2019) 'Conceptual Engineering and Semantic Deference', Studia Philosophica Estonica 12: 81-98

Posner, R. (2004) Torture, Terrorism, and Interrogation. In N.A. Davis, R. Keshen, \& J. McMahan (eds.), Torture: A Collection (pp. 291-898). Oxford: Oxford University Press

Skolnick, J.H. (2004) American Interrogation: From Torture to Trickery. In N.A. Davis, R. Keshen, \& J. McMahan (eds.), Torture: A Collection (pp. 105-28). Oxford: Oxford University Press

Smith, M. (2020) What Do Americans Think Socialism Looks Like?, YouGov, URL = https://today.yougov.com/topics/politics/articles-reports/2020/10/05/what-do-americans-think$\underline{\text { socialism- }}$ looks?fbclid=IwAR1oz3FD3hdxXEWLA25DHqDzIpzkXzyGJBImVfq6YAGKVIDN_SMu4gZ $\underline{\text { BUA8 }}$ 
Sterken, R. (2020) Linguistic Interventions and Transformative Communicative Disruptions. In H. Cappelen, D. Plunkett, \& A. Burgess (eds.), Conceptual Engineering and Conceptual Ethics (pp. 417-34). Oxford: Oxford University Press

Stokoe, E. (2018) Talk: The Science of Conversation. London, UK: Robinson

Tosi, J. \& Warmke, B. (2016) Moral Grandstanding, Philosophy and Public Affairs 44 (3): 197217

Tosi, J. \& Warmke, B. (2020) Grandstanding: The Use and Abuse of Moral Talk. Oxford: Oxford University Press

Zollman, K.J.S. (2010) ‘The Epistemic Benefits of Transient Diversity’, Erkenntnis 72 (1): 17-35 